\title{
FORMAÇÃO MÉDICA - EVOLUÇÃO DO CURSO DE MEDICINA DA UFPR
}

DOI: $10.5380 /$ rmu.v1i3.40746

Nas duas últimas décadas houve uma crescente discussão sobre Educação Médica. Questões como metodologia de ensino, sobretudo as que são centradas no aluno, a construção de currículos com objetivos específicos para cada nível de atenção, a utilização de espaços fora do ambiente hospitalar, a inserção precoce do estudante na rede de atenção do município e sua integração com a assistência são alguns dos quesitos debatidos.

Ao mesmo tempo foram criados processos de avaliação como o Provão e o ENADE.

Foi possível constatar que o ensino médico no Brasil é heterogêneo em cada um dos aspectos mencionados acima.

No ano de 2001, baseado no Projeto CINAEM, foi construída a primeira Diretriz Brasileira de Ensino Médico, que visava conferir maior homogeneidade na formação profissional.

Até então na Universidade Federal do Paraná o ensino seguia o modelo tradicional com aulas expositivas e centrado, sobretudo no Hospital, com pouca inserção na rede de atenção do município de Curitiba.

A pergunta que sempre se fazia e ainda se faz é qual a característica do médico que se pretende formar no país.

Este questionamento se deve ao produto do estudo sobre como a Educação Médica é realizada no Brasil. O que se questiona? A baixa produção de conhecimentos, currículos que não se modificaram ao longo das últimas décadas, mantendo o mesmo modelo, carga horária excessiva dificultando o estudo fora da Universidade e a busca por informações que não constam no conteúdo da aula, dissociação entre a teoria e a prática, entre os ciclos e as fases do curso, utilização não planejada da tecnologia e formação médica impessoal.

Para que estes aspectos sejam analisados é necessário revisitar os anos 70 para relembrarmos como a oferta de trabalho era oferecida ao profissional na ocasião e como esta oferta evoluiu.

$\mathrm{Na}$ década de 70 o médico era essencialmente um profissional autônomo. Inicialmente ocorreu crescimento do setor privado onde se desenvolvia atividade médica pela compra de serviços de saúde pelo Instituto Nacional de Assistência Médica da Previdência Social (INAMPS).

Antes do advento do Sistema Único de Saúde (SUS), a atuação do Ministério da Saúde se resumia às atividades de promoção de saúde e prevenção de doenças (vacinação), realizadas em caráter universal, e à assistência médico-hospitalar para poucas doenças; servia aos indigentes, ou seja, a quem não tinha acesso ao atendimento pelo Instituto Nacional de Assistência Médica da Previdência Social. O INAMPS foi criado em 1974 pelo desmembramento do Instituto Nacional de Previdência Social (INPS), que hoje é o Instituto Nacional de Seguridade Social (INSS); era uma autarquia filiada ao Ministério da Previdência e Assistência Social (hoje Ministério da Previdência Social), e tinha a finalidade de prestar atendimento médico aos que contribuíam com a previdência social, ou seja, aos empregados de carteira assinada. O INAMPS dispunha de estabelecimentos próprios, mas a maior parte do atendimento era realizada pela iniciativa privada; os convênios 
estabeleciam a remuneração por procedimento, consolidando a lógica de cuidar da doença e não da saúde. O movimento da Reforma Sanitária nasceu no meio acadêmico no início da década de 70. Em meados da década de 70, com o fim do milagre econômico, ocorreu uma crise do financiamento da previdência social, com repercussões no INAMPS. Ao longo da década de 80 o INAMPS passaria por sucessivas mudanças com universalização progressiva do atendimento, já numa transição com o SUS. A 8a Conferência Nacional de Saúde foi um marco na história do SUS por vários motivos. Foi à primeira CNS a ser aberta à sociedade em 1986; além disso, foi importante na propagação do movimento da Reforma Sanitária. Da 8a CNS resultou na implantação do Sistema Unificado e Descentralizado de Saúde (SUDS), um convênio entre o INAMPS e os governos estaduais, mas o mais importante foi ter formado as bases para a seção "Da Saúde" da Constituição brasileira de 5 de outubro de 1988. A Constituição de 1988 foi um marco na história da saúde pública brasileira, ao definir a saúde como "direito de todos e dever do Estado". A implantação do SUS foi realizada de forma gradual: primeiro veio o SUDS; depois, a incorporação do INAMPS ao Ministério da Saúde; e por fim a Lei Orgânica da Saúde (Lei no 8.080, de 19 de setembro de 1990) fundou o SUS. O INAMPS só foi extinto em 27 de julho de 1993 pela Lei no 8.689.

Com as modificações descritas passou-se a estimular a atividade médica especializada com remuneração privilegiada e cargas horárias menores.

Com a ampliação da rede própria do Estado o médico passou a ser contrato pelo estado para compor esta rede. $\mathrm{O}$ assalariamento médico passou a ser modalidade crescente de inserção no mercado de trabalho.

Ao mesmo tempo houve expansão de sistemas de pré-pagamento, seguros saúde e cooperativas médicas como alternativas para acesso individual ou coletivo a serviços de saúde.

Este processo continuou e na década de 90 houve expansão da rede de serviço público, especialmente a Municipal.

Com a necessidade de regular o mercado, uma vez que o setor público contava com serviços próprios, houve por parte do governo incentivo para criação de escolas médicas como um programa de governo com a finalidade de regular o mercado.

Nesta época houve uma estratificação técnica e social do trabalho médico. Passaram a existir cargas de trabalho valorização e remuneração diferenciadas para as distintas modalidades de prática.

Estas medidas redundaram na perda por parte do profissional médico na definição dos serviços e boa parte do controle sobre os instrumentos - clientes e remuneração.

A relação entre o médico e o paciente se modificou. $O$ paciente deixou de escolher livremente o médico e o médico deixou de ser o responsável pelas condições em que o atendimento ocorria.

Em paralelo a todos estes fatos houve um incremento no desenvolvimento da tecnologia aplicada à medicina, o volume de informações aumentou rapidamente. A utilização da tecnologia como elemento essencial na fase diagnóstica História Clínica e do Exame Físico.

da doença diminuiu, na prática, a importância da

A possibilidade de se aproximar do indivíduo como um todo é o que torna a consulta médica individual, exclusiva e privada. É por meio da consulta que se estabelece a confiança na relação do médico para com o paciente. Além disso, este contato propicia que o médico aprenda aspectos da realidade social do paciente, indispensáveis para a produção dos cuidados adequados a cada nível de extração social.

A forma como o sistema se organizou e ainda se organiza desqualifica essa relação e descaracteriza a individualização que a consulta propicia.

Com a introdução da tecnologia, o olhar médico ampliou-se para além dos sintomas e passou a buscar alterações aonde ainda não existe lesão. Passou a ver o risco antevendo lesão futura. $\mathrm{Na}$ 
abordagem clínica pertencer a um grupo de risco tem o mesmo efeito de qualquer sinal clínico. 0 risco, em algumas ocasiões, passou a ser objeto de diagnóstico em si.

A profissão médica é fundamentada em uma seleção histórica de regras de comportamento moral, que devem garantir uma prestação eficiente de exercícios profissionais com a finalidade de servir ao homem e à humanidade, no agir com beneficência.

Segundo o Professor José Roberto Goldim, biólogo da Universidade Federal do Rio Grande do Sul a profissão médica se fundamenta em três pilares - O pilar da Ética, da Moral e o da Lei.

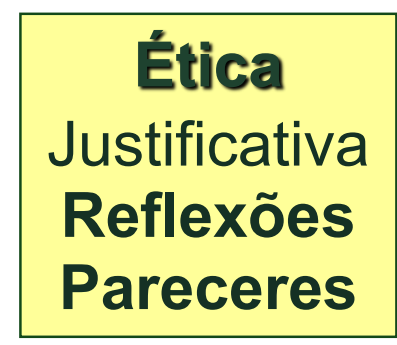

\section{Ação}
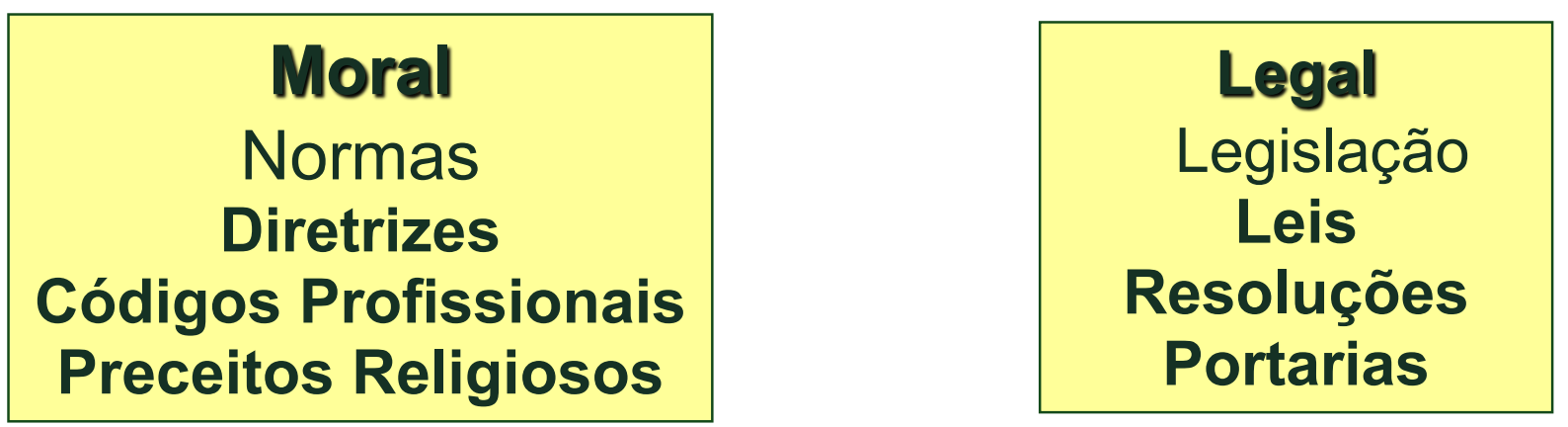

As escolas médicas por sua vez, são instituições complexas, articuladas nos espaços da saúde e educação alinhada com os princípios da profissão. Implica na existência de uma diversidade de inserções de trabalho e é constituída por identidades distintas em seu interior.

A principal reforma do ensino médico no mundo ocidental no século $X X$, desencadeada pelo relatório Flexner, o qual estabeleceu bases para uma nova medicina, nova prática médica e nova maneira de formar médicos.

Os processos de modificação no ensino médico envolvem processos que podem ser inovadores, de reforma ou de transformação.

Na Universidade Federal do Paraná tivemos duas reformas mais recente no final da década de 90 e em 2010.

Neste ano uma nova Diretriz Curricular foi editada enfatizando o ensino da Atenção Primária e a inserção do Ensino em unidades de saúde inclusive nos serviços de emergência. 
Num cenário de transformação social, não ocorrerá transformação automática da escola médica, determinada pelas novas relações estruturais. Haverá sim uma conjuntura mais favorável para que as transformações aconteçam. Refletidas e em consonância com os princípios da profissão.

Miguel Ibraim Abboud Hanna Sobrinho Professor Assistente do Departamento de Clínica Médica Chefe do Departamento de Clínica Médica

\section{REFERÊNCIAS BIBLIOGRÁFICAS}

1. Bioética - Universidade Federal do Rio Grande do Sul - José Roberto Goldim.

2. Laura Feuerwerker - Além do Discurso de Mudança na Educação Médica.

3. Ministério da Saúde - www.saúde.gov.br-07/07/2014. 